hairs of the upper edge of the male fore tibiae are longer. The middle and hind coxae are black, the fore coxae more or less fuscous : tarsi black, the remainder of the legs variable in color from fuscous to piceous. The front metatarsi of the male enlarged, ovoid, the distal third of the inner side is excised for the reception of the remainder of the tarsus, which thus is not attached at the tip of the metatarsus. The front tibiae of the males are somewhat thickened. Wings cinereous-hyaline, stigmal spot faintly brown, neuration normal.

Seven males, twelve females and the gynandromorphic specimen.
Dubois (IX. 6, I895) and Little Wind River (IX. 2, I895) Wyoming.

This species seems to be allied to seriata, Loew, of the Eastern States, which also has ovate metatarsi in the males. As Dr. Loew does not mention the place of articulation of the second joint, it may be presumed that it is terminal to the metatarsus as in the other forms of the genus. Moreover, the middle tibiae of the male seriata are provided with rather long pubescence, a character not observable in Wheeleri.

\section{A NEW COCCID ON ROOTS OF RUBUS.}

\author{
BY T. D. A. COCKERELL.
}

Phenacoccus rubivorus, n. sp. $-9-\mathrm{Hem}-$ ispherical, with the form of a half-pea, distinctly segmented, pale pinkish, thinly covered with white mealy secretion; no cottony appendages. Boiled in liquor potassae, they stain the liquid amber yellow, and the skin becomes colorless. Anal ring with 6 hairs. Caudal tubercles very low and inconspicuous, with short bristles. Legs and antennae very pale brownish; claw with a small denticle on inner side; digitules slender, with small knobs. Antennae 9-jointed, formula approximately 92(35)6(47 I)8. The following measurements are in $\mu$ :-

Antennae segments ; (I.) 36 , (2.) $5 \mathrm{I}$, (3.) $48,(4) 39,.(5) 45$, (6.) 43 , (7.) 39 , (8.) 30, (9.) 69. Middle legs; femur + trochanter, 222 ; tibia, I74; tarsus, 90 ; claw, 27. Of course these measurements will vary, no two individuals being exactly alike.

The females studied contained very welldeveloped embryos. These showed small spines, round glands, and a small patch of spines on each lateral margin of each segment.

$H a b$ - Beulah, New Mexico, about 8,00o ft. alt., end of March, I9or, on roots of Rubus strigosus. Collected by Wilmatte P. Cockerell.

This interesting species does not have the superficial appearance of a Phenacoccus, though the antennae and legs are as in that genus. I suspect that when we know the male it will turn out to be congeneric with the little-known European Tetrura rubi described by Lichtenstein, concerning which see Entomologist, 1900, p. 86.

\section{A NEW SPECIES OF CHRYSOPA FROM TEXAS.*}

BY JESSE F. MCCLENDON.

Chrysopa bimaculata, sp. nov. Length to tip of wings $11.5 \mathrm{~mm}-13.5 \mathrm{~mm}$., alar expanse $2 \mathrm{I}-25 \mathrm{~mm}$.

Mouth short, antenna slightly shorter

* (Contributions from the Zoological Laboratory of the University of Texas, No. 19.) 
than the wing; prothorax broader than long; wings moderately narrow, anterior pair slightly pointed, posterior more acutely, in anterior wing divisory veinlet of third cubital areole exceeding the first cross-vein of the first radial sector.*

Face stramineous, vertex green, gular region stramineous, segments of palpi black, ineous, darker towards apex, first article with a red longitudinal line above; thorax green, paler beneath, prothorax with a luteo-rufous streak on each side from anterior to posterior margin; abdomen green; legs pale green, tarsi yellowish, ungues fuscous; wing veins green, in anterior wing all cross veins black or varied with black, in posterior wing costal

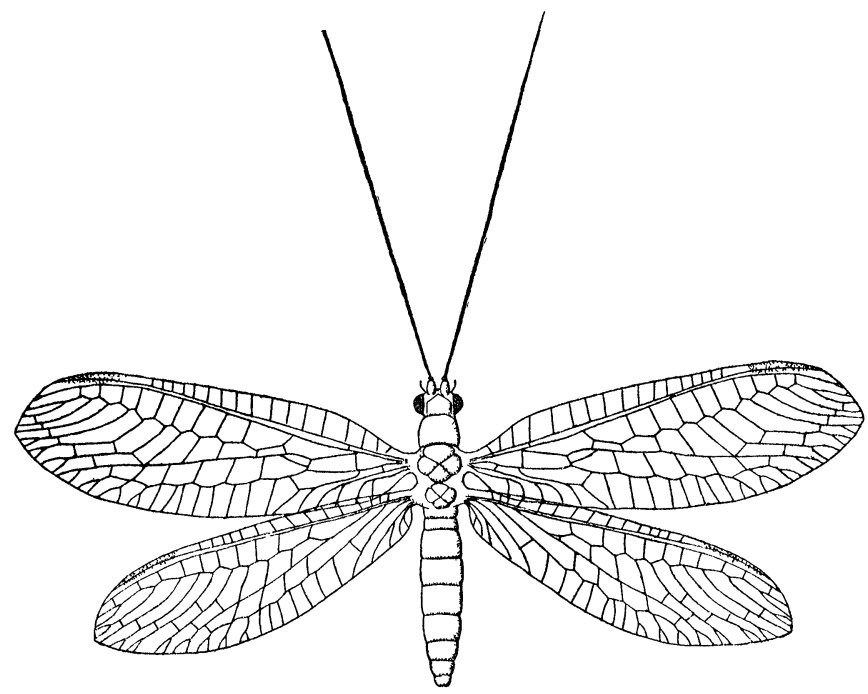

their articulations colorless, antennae stram-

* The position of this veinlet has been noted in descriptions of many species of Chrysopa, but on examining a number of specimens of Chrysopa externa, I found it to vary so much as to be of no value in determining that species. Whether it varies in C. bimaculata, I am unable to decide on account of the small number of specimens in my possession. cross-veins and a few others black, pterostigma light green.

Coloration of alcoholic specimen: green faded to pale yellow, line on first article of antennae fuscous, streak on prothorax faded out, black retained.

Four specimens from Laredo, Texas. August, I900.

\section{A. SMITH \& SONS, 146-148 WILLIAM ST., New York. MANUFACTURERS AND IMPORTERS OF GOODS FOR EHTOMOLOGISTS, \\ Klaeger and Carlsbad Insect Pins, Setting Boards, Folding Nets, Locality and Special Labels, Forceps, Sheet Cork, Etc. Other a rticles are being added, Send for List.}



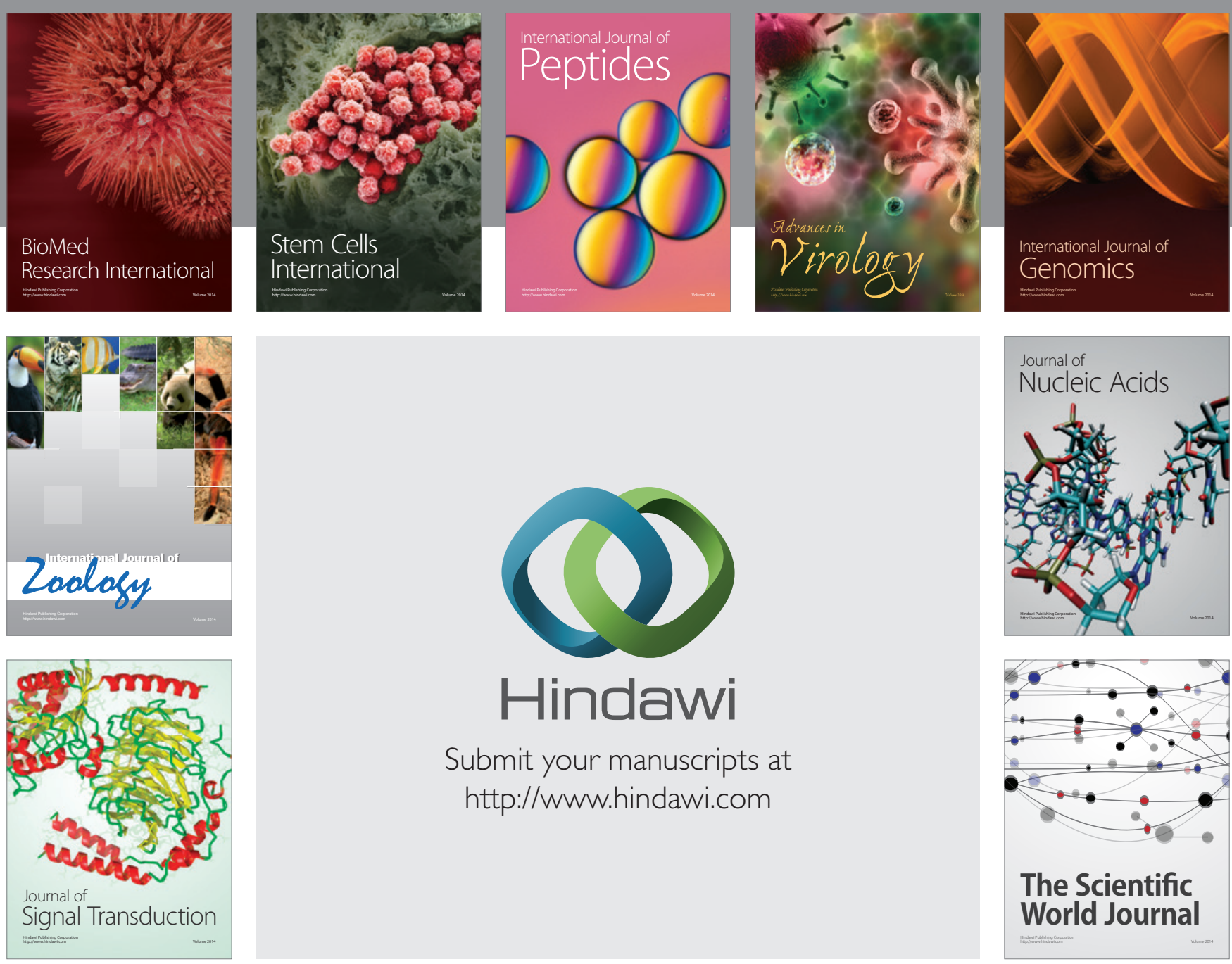

Submit your manuscripts at

http://www.hindawi.com
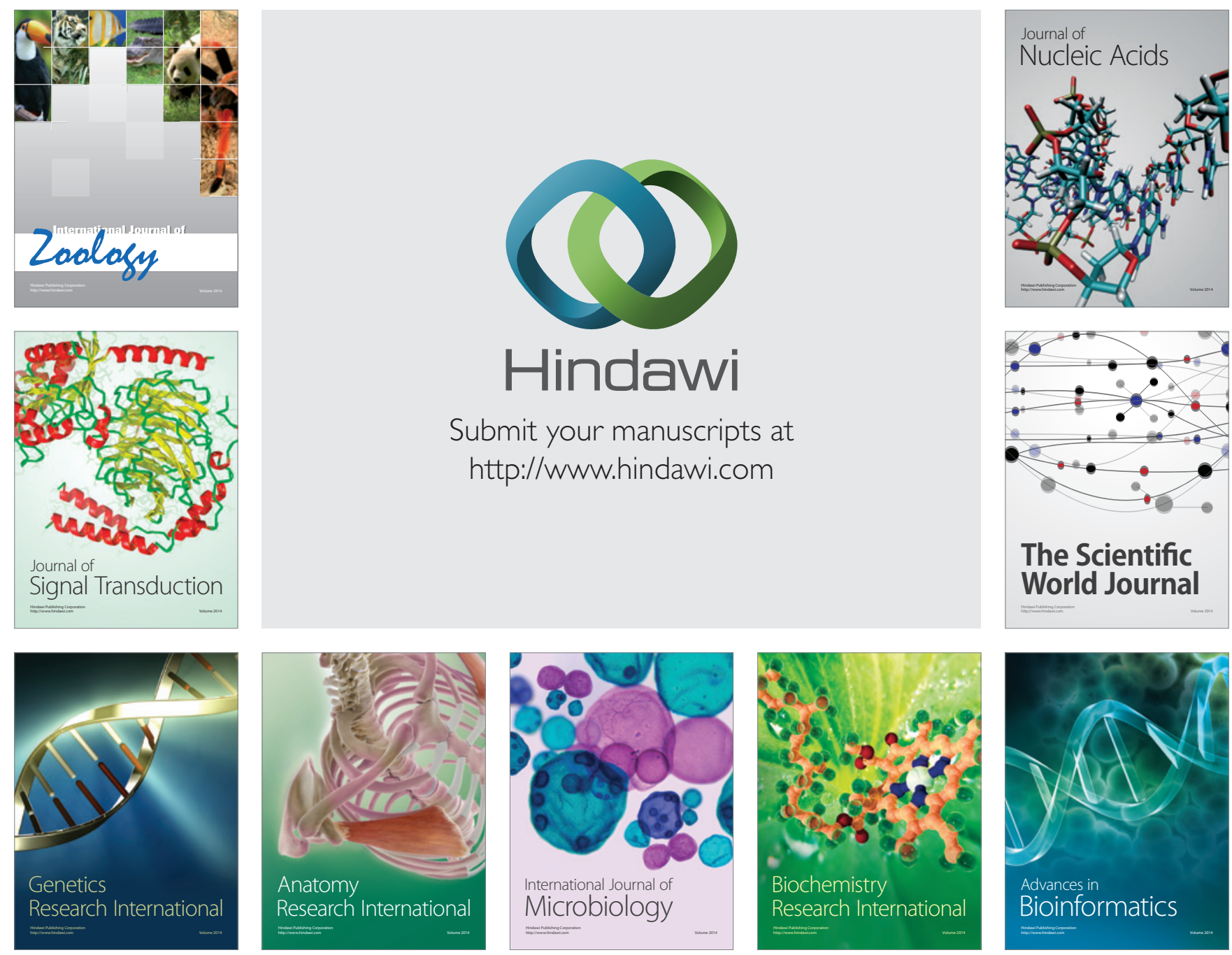

The Scientific World Journal
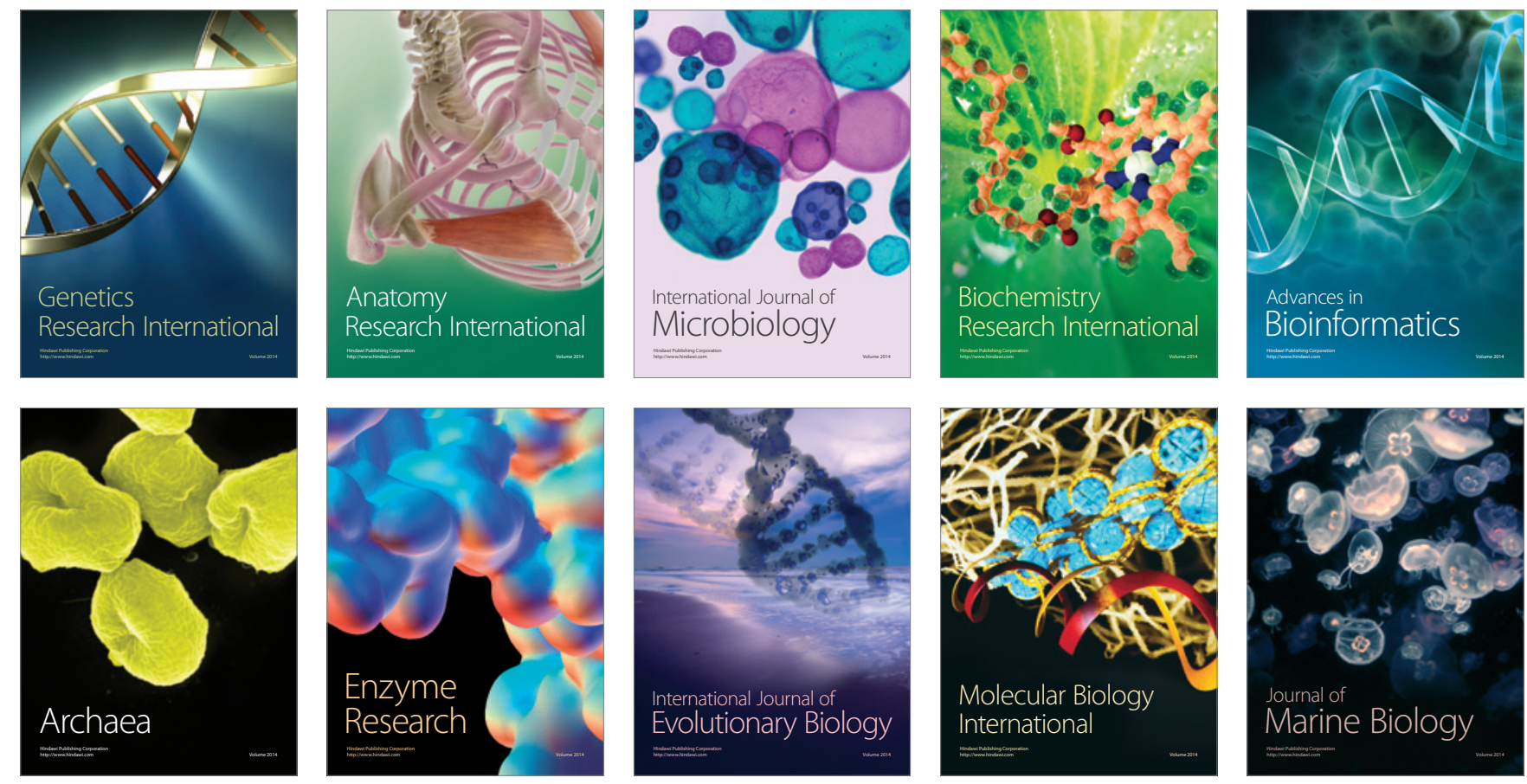